\title{
Enzymatic Synthesis of Glyceride Esters in Solvent-Free System: Influence of the Molar Ratio, Lipase Source and Functional Activating Agent of the Support
}

\author{
Larissa Freitas, Victor H. Perez, Julio C. Santos and Heizir F. de Castro*
}

\author{
Escola de Engenharia de Lorena, Universidade de São Paulo, CP 116, 12606-970 Lorena-SP, Brazil
}

\begin{abstract}
Este trabalho avaliou a influência de fatores que afetam a síntese de ésteres glicéricos, tais como: razão molar entre os reagentes, fonte de lipase e tipo de agente de ativação do suporte obtido pela técnica sol-gel. Foram empregadas preparações comerciais de lipases imobilizadas em partículas de polissiloxano-álcool polivinílico (POS-PVA) previamente ativadas com diferentes agentes (glutaraldeído, metaperiodato de sódio e carbonildiimidazol). Esses resultados foram comparados com aqueles obtidos por preparações de lipase imobilizada disponíveis comercialmente (Lipozyme IM ${ }^{20}$, Novozym 435, Lipozyme RM IM e Lipozyme TL IM). O meio reacional contendo excesso de glicerol favoreceu a síntese de ésteres glicéricos e a Lipozyme $\mathrm{IM}^{20}$ foi a preparação de lipase imobilizada mais adequada para a síntese, atingindo conversões molares maiores que 94\%. O uso da lipase CALB L imobilizada em POS-PVA também alcançou resultados satisfatórios (cerca de $80 \%$ de conversão) possibilitando a formação de $36 \%$ de 2,3 diidroxipropil dodecanoato (monolaurina).
\end{abstract}

This work assessed the influence of important factors that affect the synthesis of glyceride esters in solvent-free systems, such as: glycerol/fatty acid molar ratio, lipase source and activating agent of the support obtained by the sol-gel technique. Commercial lipase preparations were immobilized on polysiloxane-polyvinyl alcohol particles (POS-PVA) previously activated with different agents (glutaraldehyde, sodium metaperiodate and carbonyldiimidazole) and their performance on the esterification reaction was compared with commercial preparations of immobilized lipase (Lipozyme IM ${ }^{20}$, Novozym 435, Lipozyme RM IM and Lipozyme TL IM). The reaction medium containing excess glycerol favored the glyceride ester synthesis and the Lipozyme $\mathrm{IM}^{20}$ was found to be the most suitable immobilized lipase preparation, attaining molar conversions higher than 94\%. The use of CAL B Lipase immobilized on POS-PVA also provided satisfactory performance (conversion of about $80 \%$ ) and allowed the formation of $36 \%$ wt of 2,3-dihydroxypropyl dodecanoate (monolaurin).

Keywords: glycerides, lipase, esterification, hybrid support, immobilization

\section{Introduction}

The demand of the industries to operate their processes under sustained conditions such as green chemistry or clean technology systems is becoming an important issue nowadays and thus requests the availability of tailored biocatalysts to operate under these conditions. ${ }^{1}$ Therefore, the need for developing active and stable immobilized biocatalysts for subsequent use in biotransformations has been highlighted. ${ }^{2}$ Among the most important biocatalysts carrying out novel reactions in both aqueous and non aqueous media, lipases stand out due to their ability to utilize a wide spectrum of substrates, high stability towards

*e-mail: heizir@dequi.eel.usp.br extremes of temperature, $\mathrm{pH}$ and organic solvents, and chemo-, regio- and enantioselectivity. ${ }^{3-5}$

Although most enzymatic syntheses are performed in presence of organic non-polar solvents, ${ }^{6}$ the elimination of these compounds is technically feasible and offers significant cost savings. In addition, reactions performed in solvent-free systems (SFSs) have several advantages, such as volumetric productivities higher than in organic medium and the possibility that the remaining substrates can be easily separated from the products and readily recycled. Furthermore, the absence of solvents generally makes the processes environmentally friendlier, since most solvents are toxic and polluting agents.?

This work aimed to establish appropriate conditions for monoglycerides synthesis by direct esterification of glycerol 
with dodecanoic acid (lauric acid) in solvent free system using lipase immobilized in polysiloxane-polyvinyl alcohol particles. Monoglycerides constitute the main category of emulsifiers used in pharmaceutical formulations and prepared foods. In the pharmaceutical industry, monoglycerides are used as binders in tablets, in slow-release drugs and as emollients for transdermal products. In the food industry, they are used to stabilize emulsions in sauces, ice creams and baked goods. ${ }^{8}$ Additionally, monoglycerides are intermediates for lipid synthesis and liquid crystals. ${ }^{9}$

\section{Experimental}

\section{Materials}

Several crude lipase preparations manufactured from reputable companies include liquid samples of Candida antartica B (CAL B), Thermomyces lanuginosus (Lipolase and Lipozyme TL 100L) from Novozymes (Araucaria, PR, Brazil); Pseudomonas fluorescens (Lipase AK) and Burkholderia cepacia (Lipase PS) from Amano Pharmaceuticals, Japan, and porcine pancreatic lipase (Type II) and lipase from Candida rugosa (Type VII) from Sigma Co (USA). All lipases were used as received without further purification, even the liquid samples provided by Novozymes. Commercial immobilized lipases as Lipozyme $\mathrm{IM}^{20}$, Novozym 435, Lipozyme RM IM and Lipozyme TL IM received as gift samples from Novozymes were also tested. Tetraethoxysilane was acquired from Aldrich Chemical Co. (Milwaukee, WI, USA). Glutaraldehyde $(25 \% \mathrm{~m} / \mathrm{v})$, hydrochloric acid (minimum 36\%), ethanol (minimum 99\%) and polyvinyl alcohol (MW 72,000) were supplied by Reagen (Rio de Janeiro, RJ, Brazil). Carbonyldiimidazole and dimethyl sulfoxide (DMSO) came from Aldrich Chemical Co. (Milwaukee, WI, USA) and sodium metaperiodate from Nuclear (São Paulo, SP, Brazil). Polyethylene glycol (molecular weight-1500) was provided by Reagen (SP, Brazil). Substrates for esterification reactions: propane-1,2,3triol (glycerol) and dodecanoic acid (lauric acid) were purchased from Merck (Darmstadt, Germany) and were dried over $0.32 \mathrm{~cm}$ molecular sieves (aluminum sodium silicate, type $13 \mathrm{X}$-BHD Chemicals, Toronto, Canada), previously activated in an oven at $350^{\circ} \mathrm{C}$ for $6 \mathrm{~h}$. Other reagents were hexane (Quimex-Brazil), ethyl acetate (Reagen-Rio de Janeiro, Brazil), and tetradecane (minimum 99\%, FlukaGermany).

\section{Polysiloxane-polyvinyl alcohol synthesis}

A polysiloxane-polyvinyl alcohol (POS-PVA) hybrid composite was prepared by hydrolysis and polycondensation of tetraethoxysilane. ${ }^{2}$ The reagents TEOS $(5 \mathrm{~mL})$, ethanol $(5 \mathrm{~mL})$, and PVA solution $2 \%(\mathrm{~m} / \mathrm{v})(6 \mathrm{~mL})$ were carefully mixed and stirred for $5 \mathrm{~min}$ at $60{ }^{\circ} \mathrm{C}$, followed by addition of two or three drops of concentrated $\mathrm{HCl}$, in order to catalyze the reaction. After an incubation period of $40 \mathrm{~min}$, the material was transferred to micro wells of tissue culture plates (disc shape) and kept at $25^{\circ} \mathrm{C}$ until complete gel solidification (formation of the interpenetrated network of POS-PVA). Then, the spheres were ground in a ball mill to attain particles with 80 MESH (Tyler standard). Specific details concerning the morphological and chemical properties of the support are given elsewhere. ${ }^{10}$ The activation of POS-PVA particles was carried out with $2.5 \%$ $(\mathrm{m} / \mathrm{v})$ glutaraldehyde at $\mathrm{pH} 7.0$ for $1 \mathrm{~h}$ at room temperature, followed by exhaustive washings with distilled water. In another set of experiments, the support was also activated with either carbonyldiimidazole or sodium metaperiodate following the methodology described by Carneiro da Cunha and co-workers ${ }^{11,12}$

\section{Lipase immobilization onto POS-PVA particles}

Activated POS-PVA particles were soaked into hexane under stirring $(100 \mathrm{rpm})$ for $1 \mathrm{~h}$ at $25{ }^{\circ} \mathrm{C}$. Then, excess hexane was removed and lipase was added at a ratio of 1:4 gram of enzyme per gram of support. PEG-1500 was added together with the enzyme solution at a fixed amount ( $5 \mathrm{mg} \mathrm{g}^{-1}$ of support). Lipase-support system was maintained in contact for $16 \mathrm{~h}$ at $4{ }^{\circ} \mathrm{C}$ under static conditions. The immobilized lipase derivatives were filtered (nylon membrane 62HD from Scheiz Seidengazefabrik AG, Thal Schweiz, Switzerland) and thoroughly rinsed with hexane. This procedure allows attaining almost full retention of enzyme on the support (higher than $80 \%$ ). ${ }^{10,13}$ The hydrolytic activities of the immobilized systems are shown in Table 1 .

Table 1. Values for hydrolytic activity of the tested immobilized lipases

\begin{tabular}{lc}
\hline Enzymatic preparation & Hydrolytic activity $^{\mathrm{a}}(\mathrm{U} / \mathrm{g})$ \\
\hline CALB L $^{\mathrm{b}}$ & 44.3 \\
Lipolase $^{\mathrm{b}}$ & 723 \\
Candida rugosa $^{\mathrm{b}}$ & 280 \\
Lipase AK (Amano 20) $^{\mathrm{b}}$ & 617 \\
Lipase PS (Amano) $^{\mathrm{b}}$ & 911 \\
Lipozyme TL 100 L $^{\mathrm{b}}$ & 730 \\
Porcine pancreatic lipase $^{\mathrm{b}}$ & 472 \\
Lipozyme IM $^{20 c}$ & 234 \\
Novozym 435 $^{\mathrm{c}}$ & 37.2 \\
Lipozyme RM IM $^{\mathrm{c}}$ & 67.4 \\
Lipozyme TL IM $^{\mathrm{c}}$ & 1290 \\
\hline
\end{tabular}

${ }^{a}$ Olive oil hydrolysis, determined as methodology of Soares et al. ${ }^{14}$ ' Immobilized derivatives on POS-PVA. 'Commercially available immobilized systems. 
General procedure for esterification reactions

Esterification reactions were carried out in a closed spherical glass reactor containing $25 \mathrm{~g}$ of medium with suitable amounts of glycerol and lauric acid and $0.5 \mathrm{~g}$ of immobilized lipase preparations. The mixture was incubated at $45-60{ }^{\circ} \mathrm{C}$ with continuous shaking at 200 rpm. Experiments were carried out at various lauric acid/glycerol molar ratio, with different sources of lipases, which were immobilized on POS-PVA activated with different compounds, except for the commercial immobilized enzymes. The ester content was quantified by measurements of the residual lauric acid in the reaction mixture. For these measurements, samples (150-200 mg) were diluted in $10 \mathrm{~mL}$ of an ethanol/ acetone 50:50 (v/v) mixture and titrated (digital burette, Hirshmann-EM Techcolor) with $\mathrm{KOH}$ solution in ethanol $\left(0.02 \mathrm{~mol} \mathrm{~L}^{-1}\right)$ using phenolphthalein as the endpoint indicator.

\section{Gas chromatography analysis}

Mono-di and triacylglycerols were analyzed by gas chromatography using a Varian 3800 model equipped with flame-ionization detector and with a $(10 \mathrm{~m} \times 0.25 \mathrm{~mm} \times$ $0.12 \mu \mathrm{m}$ CP Sil 5CB) capillary column (Varian, Inc. Corporate Headquarters, Palo Alto, CA, USA). The chromatograms were processed using a Varian data integrator version 4.51 computational program. Hydrogen was used as the carrier gas with a flow rate of $2 \mathrm{~mL} \mathrm{~min}^{-1}$. The detector and injector temperatures were $350{ }^{\circ} \mathrm{C}$. The column temperature was set to $80^{\circ} \mathrm{C}$ for $1 \mathrm{~min}$ and was then programmed at $20{ }^{\circ} \mathrm{C} \mathrm{min}-1$ to $320{ }^{\circ} \mathrm{C}$, which was maintained constant for $2 \mathrm{~min}$. Other conditions were split ratio of $1: 20$ and attenuation equal to 1 . The reaction medium was previously treated for extraction of water and glycerol. ${ }^{15}$ The organic phase was dissolved in $1 \mathrm{~mL}$ of hexane/ethyl acetate which contained tetradecane as internal standard, and a direct injection was carried out into the gas chromatograph. For the determination of calibration curves, solutions of pure lauric acid, 2,3-dihydroxypropyl dodecanoate (monolaurin), (1-dodecanoyloxy-3-hydroxypropan-2-yl) dodecanoate (dilaurin) and 2,3-didodecanoyloxypropyl dodecanoate (trilaurin) (Sigma-Aldrich) were used.

\section{Calculation of conversion and productivity}

The percentage of conversion to ester $(\mathrm{X}, \%)$ was calculated from the disappearance of the free fatty acid from the reaction medium and the productivity $(\mathrm{P}, \mathrm{mmol}$ converted fatty acids $\mathrm{h}^{-1}$ ) was calculated by dividing the maximum ester production by the time taken to reach it.

\section{Results and Discussion}

\section{Influence of glycerol/lauric acid molar ratio}

Due to the well-known behavior of the Lipozyme $\mathrm{IM}^{20}$ in several reaction systems, ${ }^{16-19}$ initial experiments were conducted with this lipase preparation. In this set of runs, the effect of varying the ratio of glycerol to lauric acid was investigated and the results were evaluated by measuring the lauric acid consumed.

As shown in Figure 1, the consumption of lauric acid was strongly dependent on the reactants molar ratio, and the results suggested that glycerol in excess favored the synthesis of glyceryl laurate. In the presence of equimolar amounts of reactants, the consumption of lauric acid was $3.43 \mathrm{~mol} \mathrm{~L}^{-1}$ in $4 \mathrm{~h}$ reaction. This value was decreased to $1.89 \mathrm{~mol} \mathrm{~L}^{-1}$ for substrate containing lauric acid in excess. On the other hand, using substrate with excess of glycerol, the consumption was increased to values as high as $3.74 \mathrm{~mol} \mathrm{~L}^{-1}$, which corresponds to 94.4\% molar conversion. Under such conditions, high levels of both monolaurin and dilaurin and only trace amounts of trilaurin were found (Figure 2). This behavior was similar to those already published for different reaction systems using Lipozyme as catalyst. ${ }^{17-}$ ${ }^{20}$ This fact can be explained by the hydrophilic character of the immobilizing support, which requires a higher amount of glycerol (hydrophilic) to reach high reaction conversion.

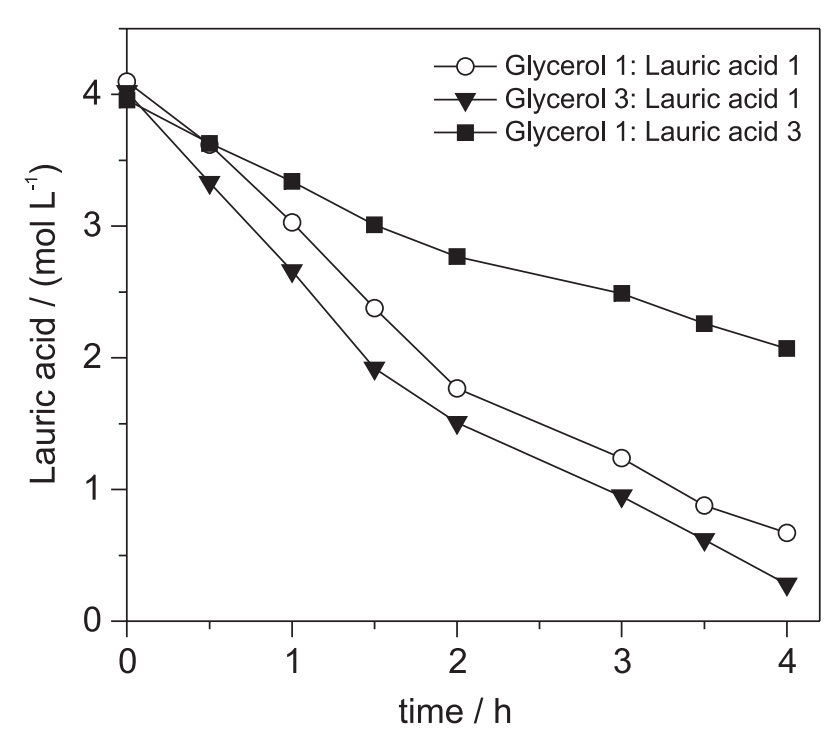

Figure 1. Curve profile for lauric acid consumption in the synthesis of glyceryl laurate using Lipozyme at different glycerol/lauric acid molar ratios. 


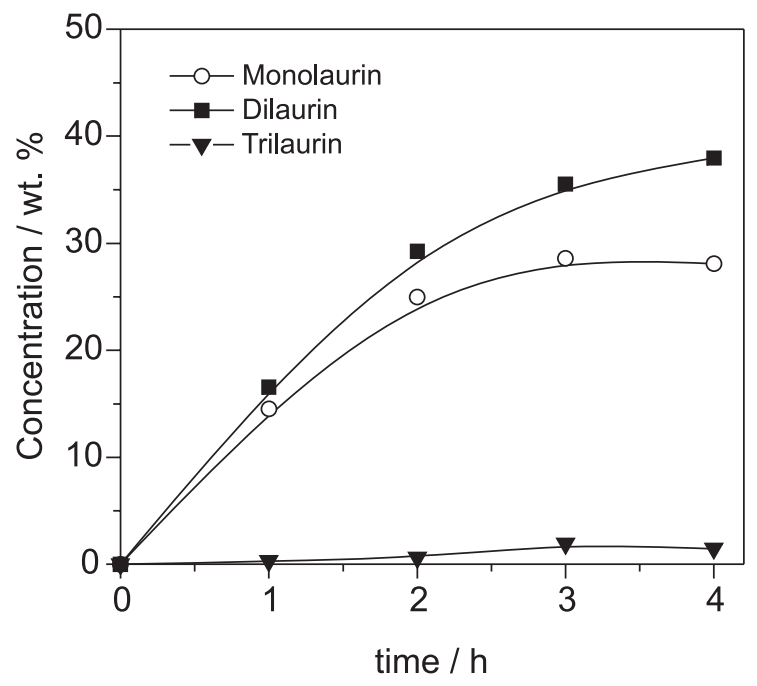

Figure 2. Curve profile for formation of monolaurin, dilaurin, trilaurin in the esterification reaction of glycerol with lauric acid catalyzed by Lipozyme (glycerol/lauric acid molar ratio 3:1).

\section{Influence of lipase source}

After having established the experimental condition that gave the highest esterification yield (glycerol/lauric acid molar ratio of 3:1), the effect of the lipase source (CALB L, Lipolase, Candida rugosa, Lipase AK, Lipase PS, Lipozyme TL 100L and pancreatic lipase) immobilized on POS-PVA activated with glutaraldehyde in the synthesis of glyceryl laurate was verified. The commercial immobilized preparations Lipozyme $\mathrm{IM}^{20}$, Novozym 435, Lipozyme RM IM and Lipozyme TL IM, reported in the literature for different applications, ${ }^{21-23}$ were also used. The results for molar conversion and productivity are shown in Figure 3.

Among all the lipases immobilized on POS-PVA, CALB L provided the highest conversion (78.8\%), which corresponded to a productivity of $0.82 \mathrm{mmol}$ of consumed fatty acids $\mathrm{h}^{-1}$. Similar conversion was achieved by the commercial immobilized lipase Novozym 435, a lipase from Candida antarctica $B$ as CALB L. It was also verified that the use of Lipozyme TL 100L immobilized on POSPVA resulted in high productivity $(2.68 \mathrm{mmol}$ consumed fatty acids $\mathrm{h}^{-1}$ ), although it has showed lower reaction conversion $(42.9 \%)$

Lower performances were also attained in reactions catalyzed by both lipases from Thermomyces lanuginosus (Lipolase) and Candida rugosa immobilized on POS-PVA, with maximum molar conversion of about $51.5 \%$ (average value). The low molar conversion obtained by Candida rugosa on POS-PVA can be justified by its restriction to catalyze the conversion of substrates containing more than 12 carbons. ${ }^{24}$

Lipases from Pseudomonas fluorescens (Lipase AK) and Burkholderia cepacia (Lipase PS) also displayed low performances, attaining maximum molar conversion of $18.5 \%$ in $48 \mathrm{~h}$ reaction and $53.3 \%$ in $30 \mathrm{~h}$ of reaction, respectively.

The porcine pancreatic lipase immobilized on POSPVA, in spite of showing lower reaction rate than Lipozyme $\mathrm{IM}^{20}$ and Novozym 435 preparations, was able to reach similar profile ( $60 \%$ of molar conversion). Although only few data are found in the literature regarding the application of porcine pancreatic lipase in esterification reactions, ${ }^{13,25}$ this preparation could be an economical alternative to other lipases.

Regarding the commercially available immobilized lipase preparations, Lipozyme RM IM reached high molar conversion ( $86.1 \%$ in $48 \mathrm{~h}$ reaction), while Lipozyme TL IM consumed only $45.0 \%$ of lauric acid in the same reaction time. The best performance was attained by Lipozyme $\mathrm{IM}^{20}$ that gave $94.4 \%$ molar conversion, corresponding to a productivity of $11.8 \mathrm{mmol}$ of lauric acid consumed $\mathrm{h}^{-1}$, which confirmed the satisfactory behavior described for this immobilized system. ${ }^{16}$

An alternative to Lipozyme $\mathrm{IM}^{20}$ would be the use of the lipase CALB L either immobilized on POS-PVA or on acrylic polymeric support as commercialized by Novozymes under the trade name Novozym 435. Both immobilized lipases showed similar performance, which may suggest the suitability of the chosen support (POSPVA) to immobilize Candida antarctica $B$ and other lipase sources. This strategy helps to analyze the attained results as a function of the lipase source rather than considering the complex interactions among all the variables affecting the lipase mediated reactions. Even though lipases from different sources are able to catalyze the same reaction, they may differ in performance. ${ }^{25}$ In addition, no correspondence was found between the hydrolytic activities (Table 1) of each tested immobilized system and their performance in the monoglycerides synthesis (Figure 3).

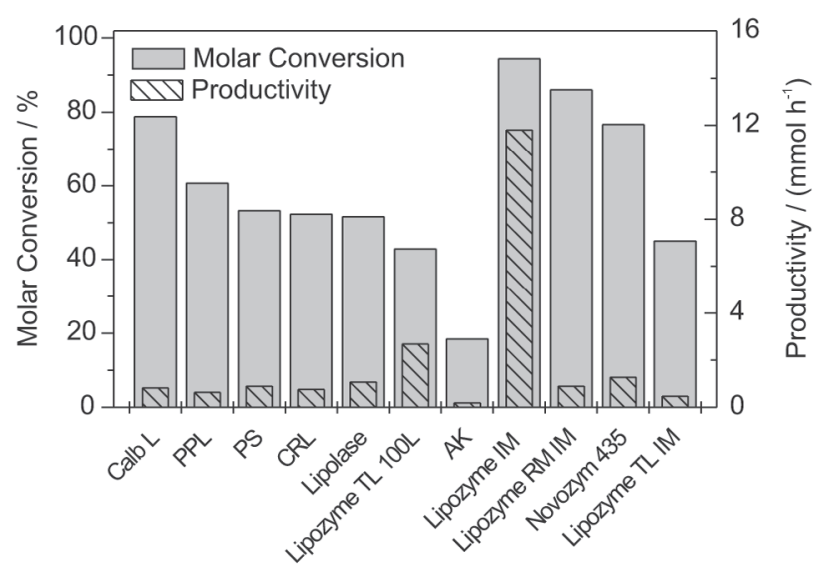

Figure 3. Productivity and molar conversion in the esterification reaction catalyzed by the tested lipase immobilized preparations. 
Therefore, some insight into the enzyme mechanism may be gained by considering a comparative analysis of the structures described for some lipases used in this work. According to Pleiss et al.,${ }^{27}$ lipases have a long, hydrophobic scissile fatty acid binding site located inside the binding pocket on top of the central $\beta$ sheet (in a crevice, on the wall of a binding funnel or in a tunnel). The protein surface on the border of this pocket is hydrophobic and it is supposed to interact with the hydrophobic substrate interface. However, an amphiphilic nature of the lipase active site had been previously proposed taking into consideration that the active sites have channel-like hydrophilic sites (used by water molecules) separated from the hidrophobic sites. ${ }^{28}$

In the present work, the observed results for Candida antartica $B$ and Rhizomucor miehei lipases are in accordance with the shape and properties of the respective scissile fatty acid binding site. Both lipases are active in substrates containing medium chain fatty acids such as lauric acid, though the Rhizomucor miehei lipase has its active catalytic triad on its surface, in a long and well defined hydrophobic crevice, in contrast to Candida antartica $B$ lipase, which has a small hydrophobic area located on the wall of the binding funnel. ${ }^{27}$

For Candida rugosa lipase, that has an aliphatic site positioned in a long tunnel inside the protein with a wide entrance involved in the binding of the scissile fatty acid chain, ${ }^{29}$ previous studies showed a clear preference for short and medium chain fatty acids, mainly $\mathrm{C}_{4}, \mathrm{C}_{8}$ and $\mathrm{C}_{10} \cdot{ }^{30}$ This could explain the poor molar conversion attained by this lipase source under the reaction conditions used here.

Another complex mechanism involved in lipase catalyzed esterification reactions may be correlated to the water concentration in the reaction system. This has a profound effect on the lipase behavior, either directly, by affecting the hydration of the enzyme, or indirectly, by changing the nature of the reaction media and/or enzyme support materials. ${ }^{26}$ In addition, water is also formed as a by-product in the same molar proportion as the main product. ${ }^{17}$ Under these conditions, the reaction involves the presence of at least two distinct liquid phases (organic and aqueous) and the distribution of water between the enzymatic solid and solution depends very much on the nature of both substrate and support material. ${ }^{26}$

In the present work, the bulk fluid phase is a mixture of organics (solvent free system) and presents high polarity due to the hydrophilic character of glycerol. Therefore care should be taken to reduce beforehand the water content in the substrate by applying dehydration techniques, such as the use of molecular sieves as described in the Experimental.
However, it is important to note that water content per se is not the controlling factor, but rather the hydration state of the enzyme molecules and the water activity of the bulk liquid phase.

The solubility of the organic phase in water has been the subject of numerous discussions and was not studied in detail here, but the correlation between the water partition to the solid phase and the nature of support will be demonstrated experimentally. In the case of Lipozyme, which consists of a lipase preparation immobilized on an ion exchange resin and has been reported to have a high water binding capacity, ${ }^{17-20}$ its use allowed to attain high reaction rate without any interference on the desirable direction, presumably through support-mediated buffering of the water content. ${ }^{17}$ This may explain also the lower performance attained by Novozym 435, a Candida antarctica $B$ lipase immobilized on a macroporous acrylic resin with a water content of $1-2 \%(\mathrm{~m} / \mathrm{m}),{ }^{26}$ although this immobilized preparation has been shown in other work to give reasonable yields in glyceryl ester production under nonaqueous reaction conditions. ${ }^{23}$

Influence of activating agents of the support on the esterification yield and process performance for monoglycerides production under the chosen conditions

Considering the satisfactory performance attained by the immobilized lipase CALB L on polysiloxane polyvinyl alcohol (POS-PVA), a further study was carried out to verify the effect of different functional activating agents (sodium metaperiodate and carbonyldiimedazole) for the support upon the immobilization procedure. It was expected that the modification of the linkage between the enzyme and the support could alter the properties of this lipase preparation in the immobilized form and consequently improve the esterification yield.

The results show that, independently of the functional agent used to activate the support, the reaction rates were similar for all the immobilized derivatives tested (Table 2). Conversion rates were maintained practically constant in the range of 75.8 to $78.8 \%$, corresponding to

Table 2. Values for molar conversion $(\mathrm{X} \%)$ and productivity $(\mathrm{P})$ in the synthesis of glyceryl laurate catalyzed by CALB L immobilized in POSPVA activated with glutaraldehyde, sodium metaperiodate, and carbonyldiimidazole

\begin{tabular}{lcc}
\hline Activating agent of the support & $\mathrm{X} / \%$ & $\mathrm{P} /\left(\mathrm{mmol} \mathrm{h}^{-1}\right)$ \\
\hline Glutaraldehyde & 78.8 & 0.82 \\
Sodium Metaperiodate & 76.7 & 0.80 \\
Carbonyldiimidazole & 75.8 & 0.79 \\
\hline
\end{tabular}

Values calculated for 48 hours of reaction. 
productivities varying from 0.79 to $0.82 \mathrm{mmol}$ of consumed fatty acids $\mathrm{h}^{-1}$, respectively.

Taking account of these findings, suitable conditions for monoglycerides production would be the use of lipase CALB L immobilized on POS-PVA previously activated with glutaraldehyde. An experiment using this immobilized system was carried out under the conditions established (reaction medium containing a glycerol/lauric acid molar ratio of $3: 1$ ) and results indicated high formation of monolaurin $(36 \%)$ as shown in Figure 4. A more thorough investigation of the parameters required to increase monoglycerides formation using this immobilized lipase is underway.

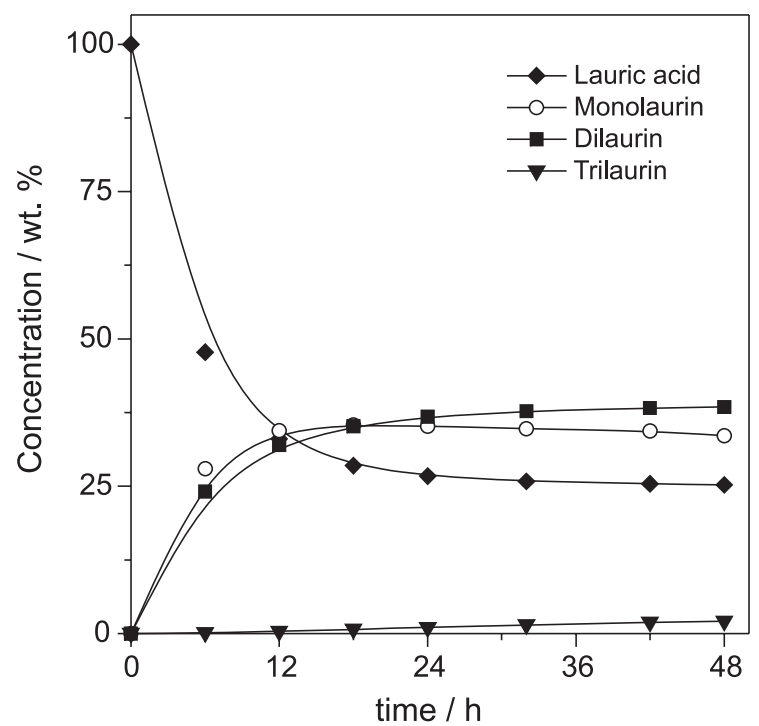

Figure 4. Curve profile for formation of the monolaurin, dilaurin, trilaurin in the esterification reaction of glycerol with lauric acid catalyzed by CALB L immobilized on POS-PVA.

\section{Conclusions}

This work was carried out to get better understanding of how different conditions influence the enzymatic glyceride ester synthesis in solvent free medium. A model system consisting of pure glycerol and lauric acid was used to determine the effects of reactants molar ratio, lipase source and functional activating agent of the support on the reaction rate. Reaction performance was found to be dependent on the glycerol/lauric acid molar ratio, requesting higher amount of glycerol to reach high reaction conversion. Although Lipozyme was found to be the most suitable immobilized lipase preparation, a potential alternative would be the use of CALB L lipase immobilized on POSPVA, which also attained high molar conversion. After $6 \mathrm{~h}$ reaction, the amount of monolaurin was about $36 \%$ wt and only trace of trilaurin was found. The results illustrated the technical feasibility of producing medium chain monoglycerides in a solvent-free system using CALB L lipase immobilized on POS-PVA previously activated with glutaraldehyde or any other chemical reactant as those tested in this work.

\section{Acknowledgments}

We acknowledge financial assistance from FAPESP and CAPES.

\section{References}

1. Bommarius, A.S.; Riebel, B.R.; Biocatalysis Fundamentals and Applications, Wiley-VCH Verlag Gmbh: Weinhein, 2004, ch. 1 and 2.

2. Bruno, L. M.; Coelho, J. S.; Melo, E.H.M.; Lima-Filho, J.L.; World J. Microbiol. Biotechnol. 2005, 21, 189.

3. Pandey, A.; Benjamin, S.; Soccol, C.R.; Nigam, P.; Krieger, N.; Thomaz-Soccol, V.; Biotechnol. Appl. Biochem. 1999, 65, 252.

4. Petkar, M.; Lali, A.; Caimi, P.; Daminati, M.; J. Mol. Catal., B: Enzym. 2006, 39, 83.

5. Dave, R.; Madamwar, D.; Process Biochem. 2006, 41, 951.

6. Gubicza, L.; Kabiri-Badr, A.; Keoves, E.; Belafi-Bako, K.; J. Biotechnol. 2002, 84, 93.

7. Foresti, M.L.; Ferreira, M.L.; Annal. Bioanal. Chem. 2005, 381, 1408.

8. Kaewthong, W.; Sirisansaneeyakul, S.; Prasertsan, P.; Process Biochem. 2005, 40, 1525.

9. Berger, M.; Schneider, M. P.; Fat Sc. Technol. 1993, 95, 169.

10. Paula, A. V.; Moreira, R. A. B.; Braga, P. L.; Bruno, L. M.; Castro, H. F.; Quim. Nova, in press.

11. Carneiro da Cunha, M. G.; Rocha, J. M. S.; Cabral, J. M. S.; Gil, M. H.; Garcia, F. A. P.; Latin Am. Appl. Res. 2002, 32, 69.

12. Carneiro da Cunha, M. G.; Rocha, J. M. S.; Garcia, F. A. P.; Gil, M. H.; Biotechnol. Tech. 1999, 13, 403.

13. Paula, A. V.; Urioste, D.; Santos, C. J.; Castro, H. F.; J. Chem. Technol. Biotechnol. 2007, 85, 281.

14. Soares, C. M. F.; Castro, H. F.; Moraes, F. F.; Zanin, G. M.; Appl. Biochem. Biotechnol. 1999, 77/79, 745.

15. AOCS; Official Methods and Recommended Practices of American Oil Chemists' Society, $5^{\text {th }}$ ed., Champaign, USA, 2004.

16. Langone, M. A. P.; Abreu, M. E.; Rezende, M. J. C.; Sant'Anna, G. L. Jr.; Appl. Biochem. Biotechnol. 2002, 98, 98.

17. de Castro, H. F.; Pereira, E. B.; Anderson, W. A.; J. Braz. Chem. Soc. 1996, 7, 219.

18. Selmi, B.; Gontier, E.; Ergan, F.; Barbotin, J. N.; Thomas, D.; Enzyme Microb. Technol. 1997, 20, 322.

19. Arcos, J. A.; Otero, C.; Hill, C. G. Jr.; Biotechnol. Lett. 1998, $20,617$. 
20. Monteiro, J. B.; Nascimento, M. G.; Ninow, J. L.; Biotechnol. Lett. 2003, 25, 641.

21. Awang, R.; Basri, M.; Ahmad, S.; Salleh, A. B.; J. Oil Sci. 2005, 54, 305.

22. Awang, R.; Basri, M.; Ahmad, S.; Salleh, A. B.; Biotechnol. Lett. 2004, 26, 11.

23. Weber, N.; Mukherjee, K. D.; J. Agric. Food Chem. 2004, 52, 5347.

24. Gomes, F. M.; Silva, G. S.; Pinatti, D. G.; Conte, R. A.; Castro, H. F.; Appl. Biochem. Biotechnol. 2005, 255.

25. Mohan, K. C.; Annapurna, D, N.; Narasimha, R. M.; Asian J. Chem. 2005, 18, 533.

26. Yahya, A. R. M.; Anderson, W. A.; Moo-Young, M.; Enzyme Microb. Technol. 1998, 23, 438.
27. Pleiss, J.; Fischer, M.; Schmid, R. D.; Chem. Phys. Lipids 1998, 93, 67.

28. Norin, M.; Haeffner, F.; Achour, A.; Norin, T.; Hult, K.; Protein Sci. 1994, 3, 1493.

29. Cygler, M.; Schrag, J. D.; Biochim. Biophys. Acta 1999, 1441, 205.

30. Janssen, A. E. M.; Vaidya, A. M.; Halling, P. J.; Enzyme Microb. Technol. 1996, 18, 340.

Received: October 16, 2006

Web Release Date: November 9, 2007

FAPESP helped in meeting the publication costs of this article. 